\title{
TEATRO E RESPONSABILIDADE OU PARA UMA FILOSOFIA DO TEATRO RESPONSÁVEL
}

\author{
Jean Carlos Gonçalves ${ }^{1}$ \\ PPGE/UFPR; LAEL/PUCSP \\ jeancarllos@ufpr.br
}

O ato é ato no confronto com outros atos, de outros sujeitos.

(Marília Amorim)

Esse artigo traz um diálogo com os textos Arte e Responsabilidade, de 1919, e Para uma Filosofia do Ato Responsável, do início da década de 20, ambos escritos por Mikhail Bakhtin. Proponho, no primeiro momento, uma conversa entre as noções de arte, responsabilidade e ato responsável. Em seguida, elaboro uma articulação teórica que une tais noções à de um possível teatro responsável e dos sentidos de responsabilidade no teatro, a partir da análise de dois enunciados de atores que viveram a mesma personagem na montagem de uma mesma peça teatral brasileira, A Máquina, de João Falcão e Adriana Falcão.

Os enunciados analisados são advindos de épocas, contextos e condições de enunciação diferentes. $O$ primeiro é um recorte de uma entrevista concedida pelo ator Wagner Moura, à seção Folha llustrada do JORNAL FOLHA DE SÃO PAULO ON LINE, em 2007, ao ser indagado sobre a preparação da peça, que foi montada em 2000. O segundo, texto de um aluno

\footnotetext{
1 Jean Carlos Gonçalves é Professor Adjunto da área de Práticas Cênicas na Universidade Federal do Paraná (UFPR), onde integra o grupo de pesquisa Linguagem e Educação (CNPq). Possui Bacharelado e Licenciatura em Teatro-Interpretação pela Universidade Regional de Blumenau (FURB). Realizou o Mestrado em Educação, na linha de pesquisa Linguagem e Educação, no PPGE/FURB, com a orientação da professora Dra. Otília Lizete de O. M. Heinig, e o Doutorado em Educação, na linha Cultura, Escola e Ensino, no PPGE/UFPR, com a orientação do professor Dr. Gilberto de Castro. Atualmente realiza o Pós-doutorado no Programa de Estudos Pós-Graduados em Linguística Aplicada e Estudos da Linguagem, na Pontifícia Universidade Católica de São Paulo (PEPGLAEL/PUCSP), sob supervisão da professora Dra. Beth Brait, com o projeto Teatro e Bakhtin em diálogo: Dimensão verbo-visual e produção de sentidos sobre a prática teatral na universidade.
} 
do Curso Superior de Produção Cênica, André Ramos, da Universidade Federal do Paraná, escrito em um blog dedicado à montagem dessa peça, realizada como espetáculo de formatura no ano de 2011.

\section{ARTE, RESPONSABILIDADE, ATO RESPONSÁVEL}

Um dos primeiros textos de Bakhtin, publicado em 1919 no almanaque diário 0 dia da Arte, em Nevel, é Arte e Responsabilidade. A principal contribuição bakhtiniana nesse texto, é a insistência na compreensão da unidade da responsabilidade, na "obrigação que tem o sujeito de unir vida e arte, arte e vida" (BRAIT, 2009). Essa discussão acontece de forma mais intensa nos textos seguintes, especialmente em Para uma Filosofia do Ato Responsável, escrito entre 1920 e 1924 e publicado somente em 1986.

Dedicar uma atenção especial aos primeiros textos de Bakhtin tem a intenção de possibilitar um diálogo entre o pensamento bakhtiniano ${ }^{2}$ e os estudos teatrais. Esse exercício de escrita pretende aproximar o teatro dos estudos referentes aos primeiros escritos do Círculo, pois encontramos nessa fase, uma preocupação com a arte e com o ato, temática que acaba por estar presente em toda a sua obra.

Bakhtin começa o texto Arte e Responsabilidade falando de três campos da cultura humana: a arte, a ciência e a vida. Ele chama a atenção para o fato de 0 indivíduo incorporar

2 Os estudos bakhtinianos ou, o pensamento bakhtiniano, é o conjunto de formulações teóricas advindas do chamado Círculo de Bakhtin. Embora existam diferentes atribuições ao termo "Círculo de Bakhtin", por parte de alguns pesquisadores, não farei uma explanação explicativa e histórica, mas o utilizo para me referir ao conjunto da obra que traz idéias produzidas por intelectuais russos, desde a segunda década do século XX. Do mesmo modo, as não menos importantes discussões sobre a autoria dos textos não terão espaço de discussão neste artigo. Ao referenciar os textos do Círculo, considero a autoria de acordo com a tradução utilizada e em respeito à edição consultada. 
esses três campos à sua própria existência. $E$ ainda fala de quão mecânico pode ser esse processo se o homem sai de uma agitação cotidiana para o momento de criação artística, como se pudesse penetrar em outro mundo de inspiração repentinamente.

Bakhtin não estava falando especificamente de teatro. Mas o teatro é arte. E uma arte que necessita ser criada, composta, encenada para então se constituir em um fenômeno artístico. Para que esse fenômeno aconteça, o indivíduo deve tornar-se inteiramente responsável por ele. Sua vida em prol da arte, sua arte em prol de sua própria vida.

Bakhtin é enfático ao dizer que "Arte e vida não são a mesma coisa, mas devem tornarse algo singular em mim, na unidade da minha responsabilidade" (BAKHTIN, 2006, XXXIII). É, portanto, na responsabilidade do sujeito que arte e vida encontram um possível caminho de unidade. Por isso justifica-se qualquer estudo em arte que considere o sujeito como centro de análise. É impossível analisar uma obra de arte, nessa perspectiva, sem olhar para o sujeito como criador, como responsável com sua vida, pela arte que põe em relação com o outro no mundo.

Bakhtin ainda fala: "Quando o homem está na arte não está na vida e vice-versa." (idem). A partir dessa concepção há sugestões para que se possa pensar um entrelugar, um entremeio de criação. Embora a frase venha com certo tom radical, qualquer conhecedor em profundidade do pensamento bakhtiniano compreende que 0 autor está falando de uma fronteira a que todo sujeito criador está suscetível. Uma fronteira que impede que o homem se ausente de sua responsabilidade pelo criado, de qualquer possibilidade de anuência com relação à sua obra.

O artista e o homem estão unificados em um indivíduo de forma ingênua, o mais das vezes mecânica: temporariamente o homem sai da "agitação do dia-a-dia" para a criação como para outro mundo "de inspiração, sons doces e orações". O que resulta daí? A arte é de uma presunção excessivamente atrevida, é patética demais, pois não the cabe responder pela vida que, é claro, não lhe anda no encalço. (BAKHTIN, 2006, XXXIII) 
Ao olhar esse trecho de relance, parece que Bakhtin estava se referindo a um contexto de montagem teatral, ao falar da agitação do dia-a-dia, da busca de inspiração... E é justamente nessa bonita elaboração teórica que ele toca em uma das feridas do teatro: a preparação para a cena. A preparação é o momento no qual o ator encontra-se na busca de formulações teóricas e práticas que justifiquem o seu estar em cena. É aí que encontro em Bakhtin respostas para meu questionamento sobre a responsabilidade no teatro. Uma responsabilidade que pode, sim, ser coletiva, mas mesmo o sendo, não exime a responsabilidade individual, visto que no encontro entre sujeito e arte a própria responsabilidade requer sua existência.

Já em Para uma Filosofia do Ato Responsável, texto escrito um pouco depois de Arte e Responsabilidade, encontra-se a responsabilidade em forma de assinatura do ato. 0 que para 0 teatro é uma importante reflexão.

Vivemos em um tempo de desmistificação da figura do diretor teatral. Um tempo onde todas as funções são experimentadas pelos participantes de grupos teatrais. A própria função de autor de teatro vem sendo questionada, por se compreender a autoria como um jogo de muitas vozes. Algumas questões norteiam essas reflexões: Uma criação teatral quando posta em cena passou por quais e quantas autorias? 0 ator, que dá vida às personagens não é também coautor textual? O diretor não é também o autor estético da obra? Quantos cortes são feitos num texto teatral ao ser encenado? Que marcações e intenções dão ao espetáculo novos tons? Seria possível uma gama de inúmeras perguntas...

Abre-se aqui uma discussão a respeito da responsabilidade pela arte. Arte e vida que deveriam estar unidas a um sujeito acabam por fazer parte de um coletivo. $O$ teatro é uma arte coletiva. Então eis uma primeira provocação que levanto: quem assina 0 ato da criação artística? Quando falamos em processo de criação estamos falando dos atos de quem?

Para Bakhtin, eu sou único e realizo atos únicos no mundo, irrepetíveis, não-indiferentes; e para o existir, o estar no mundo, não existe álibi. Não existe álibi para o ser. Sou um ser ativo e responsivo. Meus atos respondem a outros atos, numa relação de alteridade e unicidade. 
"Somente 0 ato, o acontecimento constitutivo do sujeito, o ser-acontecimento no dizer de Bakhtin, produz a articulação produtora de sentido" (AMORIM, 2009, p. 40)

Para compreender o teatro, essa relação proposta por Bakhtin é essencial. A responsabilidade pelo ato pode ser discutida aqui como a responsabilidade pela criação. Cada participante da atividade teatral assina uma parte da obra que vai a público, mas essa assinatura também tem seu centro na relação com o outro. Há uma complementação dessa teoria na seguinte discussão de Augusto Ponzio:

Bakhtin insiste particularmente na inevitabilidade do envolvimento com o outro - com
o outro concreto, e não um outro eu abstrato, teoricamente concebido como
consciência gneseológica abstrata -, que o ser responsavelmente partícipe na
unicidade de seu lugar único no mundo comporta: ser responsavelmente partícipe é
também "apreender" o outro, o que me compele à responsabilidade. A
responsabilidade pelo ato é, acima de tudo, responsabilidade pelo outro [...]. Grifo
meu. (PONZIO, 2008, p. 39)

Mesmo as tentativas de escape da responsabilidade sobre 0 ato, acabam por denunciar sua presença inevitável. Para Bakhtin, a filosofia de vida é uma filosofia moral, portanto não há como separar produto e vida, obra e autor. Assim, o ato, separado da cultura, aparece como mera subjetividade biológica. Interessante pensar que o teatro como produto de uma criação puramente humana, é fruto de atos responsáveis. Fruto de interações entre sujeitos. Cada qual com seus atos criativos, que juntos corroboram para a efetivação de uma obra artística, constituída num processo reciprocamente participativo.

Há, portanto, dois centros de valor, sobre os quais a arquitetônica do ato responsável é organizada: o meu e o do outro, que se multiplicam numa variedade imensa de outros centros de valor. Centros que precisam ser considerados, por exemplo, na análise de produções teatrais contemporâneas, seja em discursos sobre a criação teatral, em diferentes esferas, seja no próprio ato investigativo do pesquisador ao se debruçar sobre seus dados. 0 fazer teatral acontece em meio a jogos sociais, jogos nos quais os centros de valor estão presentes. Os sujeitos e seus outros. E uma criação descrita, falada, executada, um processo de montagem teatral, é um processo que acontece entre os atos responsáveis, entre a sutileza das vozes que compõem e assinam esses atos. 
Por isso, as perguntas feitas anteriormente podem ser respondidas pelo próprio Bakhtin, em Para uma Filosofia do Ato Responsável, texto em que o autor aponta para o fato de que:

\begin{abstract}
Cada um de meus pensamentos, com o seu conteúdo, é um ato singular responsável meu; é um dos atos de que se compõe a minha vida singular inteira como agir ininterrupto, porque a vida inteira na sua totalidade pode ser considerada como uma espécie de ato complexo: eu ajo com toda a minha vida, e cada ato singular e cada experiência que vivo são um momento do meu viver-agir. (BAKHTIN, 2010, p. 44)
\end{abstract}

Vemos aqui um Bakhtin que insiste na compreensão do ato como intrínseco ao próprio existir do sujeito. Abre espaço para pensar a importância do contexto do ato, e sua lógica que está justamente em compreender que o ato é uma via de mão dupla. Acontece entre sujeitos e considera os centros de valor de sua arquitetônica a partir de um ponto de vista extralocalizado e múltiplo: o "eu-para-mim", o "outro-para-mim" e o "eu-para-o-outro".

É possível por meio dessa discussão, atribuir a todos os participantes de uma criação teatral a responsabilidade participativa na obra cênica. A assinatura de todos. Os atos de todos. Mas de forma alguma pensar a responsibilidade compartilhada. Ela é de todos porque todos implica a compreensão de um coletivo de indivíduos, cada um com sua bagagem necessária de responsabilidade.

Se essa consciência começar a circular pelos espaços teatrais, pelos grupos, pelos artistas e pelas instituições onde se faz teatro, outro sentido sobre o senso de responsabilidade pode ser desencadeado no cenário artístico. 0 assumir-se responsável, o assumir-se constituído pelo outro, o assumir-se sujeito da criação, pode ser o cerne da questão que põe em foco 0 estilo artístico defendido na reflexão bakhtiniana. Um estilo que "não trabalha com palavras, mas com elementos do mundo, com valores do mundo e da vida" (BAKHTIN, 2006, p. 180). Para se trabalhar com tal estilo, e necessário um entendimento de arte como elemento da vida, elemento que é fabricado, que é feito de sujeitos para sujeitos, e que, portanto, é ato. Ato responsável. Ato assinado na articulação das diferenças, partícipe de uma cultura, de um contexto. 


\section{TEATRO, RESPONSABILIDADE, TEATRO RESPONSÁVEL}

Tudo o que pode ser feito por mim não poderá nunca ser feito por mais ninguém, nunca.

(BAKHTIN, em Para uma Filosofia do Ato Responsável)

A análise que proponho tenta averiguar a aplicabilidade da relação entre ato como responsabilidade, tal como defendida por Bakhtin, e o teatro, também como responsabilidade, sentido que ecoa dos dados dessa pesquisa. Para pensar um teatro responsável, torna-se necessário aliá-lo à noção de ato. Um acordo necessário: teatro, nesse texto, é compreendido como ato, e ato, por sua vez, na sua relação com a responsabilidade.

O primeiro fragmento de análise é um recorte de uma entrevista realizada com 0 ator Wagner Moura em 2007. Na ocasião, várias perguntas, sob diferentes prismas, elucubravam a figura do ator como celebridade, em virtude do mesmo estar participando de uma telenovela de grandes índices de audiência no Brasil. 0 recorte se justifica, pois retrata o momento em que 0 ator é questionado sobre sua participação no espetáculo teatral $A$ Máquina, de João Falcão e Adriana Falcão, que também é escopo de interesse do fragmento a ser analisado posteriormente neste artigo.

Folha: Na preparação da peça "A Máquina" [2000], você se mudou para 0 Recife para ensaiar e morou com o elenco e o diretor. Era uma disponibilidade total ao trabalho? Moura:Total. Que época boa! Todo mundo amigo, todo mundo querendo fazer aquilo. Eu já estava num momento em que queria sair de Salvador, trabalhar com outras pessoas, ver como era o teatro em outros lugares. Outro dia estava me lembrando que, em 1996, eu e Vladimir [Brichta] fizemos uma peça com José Possi Neto, em Salvador. Eu estava quase desistindo de fazer teatro. Achava que ia ser jornalista mesmo, que o teatro não ia dar certo. Ele fez um teste para a peça e eu não quis fazer. Aí os atores saíram, ele me chamou para ser testado. Fiz 
uma leitura. Ele gostou da leitura e disse: "Quero que você faça a minha peça". Eu saí correndo da escola de teatro até minha casa, na chuva. Outro dia fiquei com saudade dessa sensação que acho que perdi um pouco. A época d'A Máquina tinha um pouco isso. Tanto que, de vez em quando, vem essa ideia de voltar com "A Máquina". Eu sou sempre o cara que é contra, acho que nós não somos mais aqueles caras que fizeram aquela peça. A gente era aquele cara, queria conhecer 0 mundo, mostrar o mundo para a menina que amava. A peça hoje não ia ter mais sentido com esse elenco. (MATTOS, ARANTES, 2007)

Ao considerar que a análise, no viés bakhtiniano, é também um ato de pesquisa por considerar o gesto interpretativo do analista, meus olhares se direcionam especialmente para os dados que falam do espetáculo $A$ Máquina, e que têm relação com as questões postas até aqui, sobre 0 ato $\mathrm{e} o$ teatro como responsabilidade.

Um primeiro momento que merece análise é a resposta do ator sobre a disponibilidade para o trabalho. Uma disponibilidade que, segundo ele, foi total. Tal totalidade, provocada pela pergunta da FOLHA sobre a disponibilidade total, representada na mudança para Recife e na divisão de moradia com outros integrantes da montagem, aponta para um enunciado que engloba diferentes sentidos para a disponibilidade do ator a uma montagem. Essa entrega, encontrada também como discurso que circula na esfera de produção teatral, surge como resposta inevitável diante da pergunta que foi feita. Bakhtin, ao falar da resposta ao outro, defende a ideia de que um enunciado é uma resposta ativa ao enunciado anterior, o que nesse caso aplica-se perfeitamente, pois 0 ator responde ao já dito, ao que já se esperava que ele fosse falar.

$\mathrm{Na}$ evolução de seu dizer, o ator pondera valorativamente: Que época boa! Todo mundo amigo, todo mundo querendo fazer aquilo. 0 centro de valor de tal entrega é então, dito como bom, como positivo, e ampliado pelo sentido de beleza da amizade de todo mundo. Todo mundo querendo fazer aquilo. 0 que me provoca a pensar com Bakhtin que "ser realmente na vida significa agir, é ser não indiferente ao todo na sua singularidade." (BAKHTIN, 2010, p. 99). Fazer teatro em outra cidade, em outro contexto, torna-se algo muito bom, e a disponibilidade é total, porque está todo mundo envolvido, agindo, sendo, existindo, justamente num momento em que 
[o ator] queria sair de Salvador, trabalhar com outras pessoas, ver como era o teatro em outros lugares.

É, portanto, na decisão de ser no existir-evento, que o ato torna-se responsabilidade, pois enquanto há a ideia, o pensamento, ou mesmo a valoração apenas, a responsabilidade não pode ser consumada. "Eu existo no mundo da realidade inelutável, não naquele da possibilidade fortuita" (idem). $\mathrm{O}$ ator estava num momento em que almejava mudanças, e por isso, ao surgir a possibilidade, que poderia ser fortuita, ele age, e muda, em prol de um espetáculo a ser realizado, com outros sujeitos que também estão querendo fazer aquilo.

\begin{abstract}
Somente 0 ato responsável supera toda hipótese, porque ele é - de um jeito inevitável, irremediável e irrevogável - a realização de uma decisão; 0 ato é 0 resultado final, uma consumada conclusão definitiva; concentra, correlaciona e resolve em um contexto único e singular e já final o sentido e o fato, o universal e o individual, o real e 0 ideal, porque tudo entra na composição de sua motivação responsável; 0 ato constitui o desabrochar da mera possibilidade na singularidade da escolha uma vez por todas. (BAKHTIN, 2010, p. 80,81)
\end{abstract}

Quando 0 ator fala que ele estava quase desistindo de fazer teatro, sinaliza também para o sentido de ato responsável como possibilidade de alteridade. Isto é, se ele tivesse desistido de fazer teatro naquele momento, o que estava quase acontecendo, poderia ter se responsabilizado por dar outro rumo à sua trajetória enquanto sujeito único no mundo. Poderia ser jornalista. E, observe-se que a expressão jornalista mesmo, aparece no sentido de conformar-se com relação às expectativas de profissão.

Ao retomar sua fala sobre o espetáculo A Máquina, Wagner diz: acho que nós não somos mais aqueles caras que fizeram aquela peça. Novamente um enunciado que recorre aos sentidos da alteridade e sua relação com a responsabilidade. Por não serem mais os caras que fizeram aquela peça, perde-se o sentido de uma remontagem, e o não montá-la surge também como responsabilidade. Uma responsabilidade ao revés, que nega um ato em detrimento de outro. Para preservar aquela imagem, daqueles caras, provavelmente revolucionários e 
sonhadores com relação ao mundo, é preferivel não voltar ao espetáculo e refazê-lo em uma época e contexto distintos.

Na referência a Antônio, personagem da peça, em $A$ gente era aquele cara, queria conhecer o mundo, mostrar o mundo para a menina que amava, o ator funde vida $\mathrm{e}$ personagem, ao aproximar os ideais que os atores tinham na época da montagem, aos ideais da personagem. Aqueles caras ou aquele cara, apresentam uma relação temporal distante e saudosista com o tempo que passou, e sobre quem eram estes atores. É inevitável que nesse ponto Bakhtin seja convidado para esta conversa, com seu texto Arte e Responsabilidade, pois é aí que a "unidade de responsabilidade" ganha força de discussão.

$\mathrm{Na}$ junção de sentidos entre ator e personagem, encontram-se vida e arte, em um movimento de alteridade que faz com que os sentidos do espetáculo transcendam a própria peça enquanto arte e passem a refletir também os anseios do ator. Ator impregnado da personagem, personagem que era representada sob as condições dos anseios dos atores. Arte e homem num alto grau de constituição mútua a partir da responsabilidade como unidade possibilitada por tal ajuntamento.

O segundo fragmento a ser analisado também corrobora essa multíplice percepção:

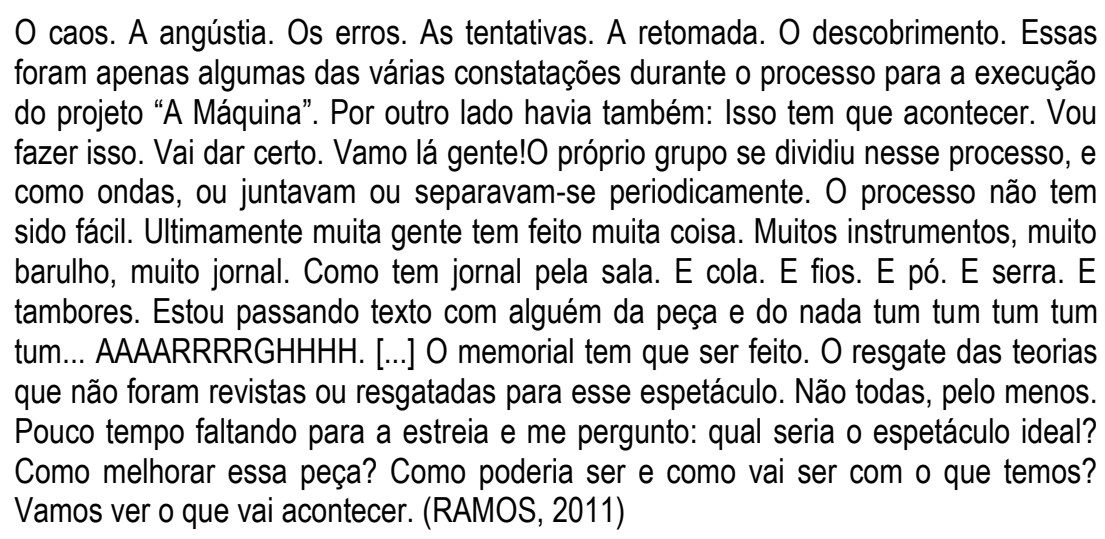

Este enunciado apresenta caos, angústia, erros, tentativas, retomada, descobrimento. Constatações humanas, e que só podem ser percebidas na relação com o objeto por que o ator é homem, em interação. $O$ processo Ihe permitiu passar por diferentes sensações. Em Para uma 
Filosofia do Ato Responsável, Bakhtin fala que o princípio arquitetônico do ato é uma espécie de contraposição concreta entre eu e o outro. E é aí que os centros de valores possibilitam a distribuição e disposição dos momentos concretos do existir.

Um mesmo objeto pode apresentar, na relação com o sujeito, diferentes aspectos valorativos, que fazem com que o mundo inteiro, ao ser correlacionado comigo e com o outro seja permeado, também, por diferentes tons emotivo-volitivos. Isso dá ao evento uma unicidade própria, vivenciada pelo sujeito, e valorada por ele.

Temos um mesmo espetáculo/evento, montado em épocas e contextos distintos, enunciado por dois sujeitos a partir de suas posições axiológicas, e cada um deles representa discursivamente o existir-evento, a partir do que é possível dizer da sua relação com o mesmo. E fora dessa relação não haveria posições ou centros de valor que pudessem retratar o vivido através das palavras, e nem por outro meio de enunciação.

O apontamento para a responsabilidade sobre a obra artística, começa a aparecer quando o ator enuncia: Por outro lado havia também: Isso tem que acontecer. Vou fazer isso. Vai dar certo. Vamo lá gente! Ao utilizar a expressão Por outro lado, o mesmo sujeito confirma a teorização sobre os centros de valor e posições axiológicas que foi desenvolvida até aqui. Ele mesmo sugere que há, então, no mínimo, dois lados, dois olhares para o processo: um das sensações que o processo lhe causou (as constatações), e outro referente ao que é necessário fazer: Isso tem que acontecer. Vou fazer isso. E é necessário porque nesse caso a esfera de produção do espetáculo é a universitária, um espaço de educação, com seus compromissos, agendas, hierarquias.

Mesmo que haja nesse fragmento um indício da responsabilidade individual do sujeito para com a obra a ser produzida, o discurso desemboca na responsabilidade mútua. $E$ isso acontece em outros momentos. No primeiro deles, ao enunciar: Vamo lá gente!, apaga-se o sentido do texto anterior: Vou fazer isso, como resposta responsável individual, em detrimento de uma aclamação à participação de todos os demais integrantes da turma no projeto. Isso acontece de outra forma, também, no silencioso enunciado: Ultimamente muita gente tem feito 
muita coisa. Pergunto: quem é muita gente? Não são todos, mas são muitos. E porque, ultimamente? Será que em período anterior não se fazia muita coisa? Ainda outra inquietação: Quais tarefas estão abarcadas em muita coisa? Muitos instrumentos, muito barulho, muito jornal? Explica-se, então, talvez, o caos que prenuncia este dizer? Essas perguntas poderiam ser respondidas em uma pesquisa que se aproximasse dos sujeitos que fizeram parte da montagem, o que não se aplica ao estudo presente.

Estou passando texto com alguém da peça e do nada tum tum tum tum tum... AAAARRRRGHHHH. Aqui a agonia do ator toma forma por meio de uma expressão não palavreada, mas dizível, e com ela vem o sentido da angústia antes dita em forma de palavra. 0 ator, que precisa de concentração, de preparação, que no fragmento da entrevista com Wagner Moura surge com total disponibilidade ao trabalho, aqui se encontra impossibilitado de exercer a sua responsabilidade para com a sua parte na criação. Uma criação que é de todos, mas como bem explicado na fala do ator, O próprio grupo se dividiu nesse processo, e como ondas, ou juntavam ou separavam-se periodicamente.

E não teria que ser assim? Há outro jeito ou saída se pensarmos na perspectiva do ato responsável de Bakhtin?

Em Arte e Responsabilidade também há uma discussão sobre a culpa como vinculada à responsabilidade. "A vida e a arte não devem só arcar com a responsabilidade mútua, mas também com a culpa mútua" (BAKHTIN, 2006, XXXIV). Analiso, a partir dessa discussão, o enunciado que finaliza o texto do ator sobre o processo: Pouco tempo faltando para a estreia e me pergunto: qual seria o espetáculo ideal? Como melhorar essa peça? Como poderia ser e como vai ser com o que temos? Vamos ver o que vai acontecer. Ao lançar questionamentos, interrogações, o sujeito demonstra sua preocupação com o processo. Uma preocupação individual, que o incomoda, e que parece lhe provocar a realizar algum tipo de mudança na sua relação com a obra artística que vem sendo executada. Porém, ao lançar a responsabilidade para um lugar vago, enunciando: Vamos ver o que vai acontecer, o sujeito se isenta da sua 
responsabilidade e também da sua culpa. Protege-se caso alguma coisa não aconteça conforme o planejado.

Há indagações, problematizações sobre o espetáculo, que não são resolvidas, ao menos discutidas pelo ator, que, vale lembrar, é um acadêmico discente, em formação, e não um ator profissional. Claro que seria presunçoso imaginar que esta responsabilidade ou culpa com relação à obra sejam apenas desse sujeito, desse ator, pois um homem apenas não consegue dar conta do coletivo. Mas lançar responsabilidade e culpa para o subjetivo lugar do coletivogrupo-turma é isentar-se sem conseqüências de qualquer maior consequência, risco e erro que todos nós, ao trabalharmos com teatro, corremos e cometemos.

\section{CONCLUSÃO RESPONSÁVEL}

É na fronteira múltipla entre responsabilidade, culpa, alteridade, valorações e posições que Bakhtin consegue tocar quando diz que não há álibi para a existência do ser no mundo. " [...] eu ocupo, no existir singular, um lugar único, irrepetível, insubstituível e impenetrável da parte de um outro" (BAKHTIN, 2010, p. 96).

Em uma situação de aula na graduação, na qual os acadêmicos reclamavam uns aos outros a ausência da responsabilidade do grupo e do engajamento de todos com relação à montagem teatral, tomei a palavra e Ihes perguntei: Quem aqui acha que está sendo irresponsável? Algum de nós pode nos dizer que não está se envolvendo com a montagem? A resposta às questões foi o silêncio. Um silêncio provocado por uma pergunta que pretendia tirar do lugar do coletivo-grupo-turma a responsabilidade falseada sobre a obra teatral, até porque um dos temas relacionados à matéria em questão era a própria responsabilidade dos integrantes deste grupo de alunos e professores sobre a obra. 
É fácil estar em um grupo e apontar a ausência da responsabilidade no âmbito do coletivo, pois quando a culpa da não-responsabilidade recai sobre um grupo, cada sujeito desse coletivo está imune a qualquer culpa individual. Como o teatro é uma obra de arte (ato) essencialmente feita em grupo, não é raro que o responsabilizar-se recaia sobre o todo, numa fuga esmaecida da responsabilidade de cada sujeito, individualmente, em sua relação com a criação artística (ato).

Os sentidos de responsabilidade que ecoam nos dois fragmentos analisados, permitem alocá-la no singular e irrepetível ato do sujeito, sempre em suas relações com o mundo (objetos e outros). Pensar a junção Teatro e Responsabilidade como um entrelaçamento necessário ao teatro contemporâneo, é vincular a responsabilidade à esfera teatral como único meio de concretização do ato de criação cênica. Na mesma perspectiva, urge discutir a noção de Teatro Responsável como ato que cabe ao sujeito, de forma que ele mesmo não encontre álibi com relação à sua responsabilidade se pretende fazer teatro (realizar 0 ato teatral) de forma responsável.

\section{REFERÊNCIAS}

AMORIM, Marília. Para uma filosofia do ato: Válido e inserido no contexto. In: BRAIT, B. (org) Dialogismo e Polifonia. São Paulo: Contexto, 2009.

BAKHTIN, Mikhail. Arte e Responsabilidade. In: Estética da Criação Verbal. 4. ed. Tradução: Paulo Bezerra. São Paulo: Ed Martins Fontes, 2006. (pp. XXXIII, XXXIV)

BAKHTIN, Mikhail. Estética da Criação Verbal. 4. ed. Tradução: Paulo Bezerra. São Paulo: Ed Martins Fontes, 2006.

BAKHTIN, Mikhail. Para uma Filosofia do Ato Responsável. Tradução aos cuidados de Waldemir Miotello e Carlos Alberto Faraco. São Carlos: Ed. Pedro e João Editores, 2010.

BRAIT, Beth. Bakhtin: Dialogismo e polifonia. São Paulo: Contexto, 2009. 
GONÇALVES, Jean Carlos. Vozes da Educação no Teatro, Vozes do Teatro na Educação: Diálogos Bakhtinianos sobre a montagem teatral na universidade, a partir da análise enunciativa de memoriais de formação em teatro. Tese de Doutorado. Curitiba: UFPR, 2011.

MATTOS, Laura.; ARANTES, Silvana. "Veja entrevista com o ator Wagner Moura, o Olavo de Paraíso Tropical" In: Folha Ilustrada. 10 de junho de 2007. Disponível em http://www1.folha.uol.com.br/folha/ilustrada/ult90u302761.shtml Acesso em 23/02/2012.

PONZIO, Augusto. A Revolução Bakhtiniana. São Paulo: Contexto, 2008.

RAMOS. André. Ei. In: A Máquina: 0 amor é o combustível. Postado em 09 de dezembro de 2011. Disponível em: http://oamoreocombustivel.blogspot.com Acesso em 23/02/2012. 